\title{
Improvement in recurring nivolumab-induced pneumonitis with repetitive administration of infliximab in a patient with head and neck cancer: A case report
}

\author{
SHOHEI UENO $^{1}$, MASATO UENOMACHI ${ }^{1}$, HITOSHI KUSABA ${ }^{1}$, MAMORU ITO $^{1}$, \\ KUNIHIRO SUZUKI ${ }^{2}$, HIROFUMI OHMURA ${ }^{1}$, KENJI TSUCHIHASHI ${ }^{1}$, \\ HIROSHI ARIYAMA $^{1}$, KOICHI AKASHI ${ }^{1}$ and EISHI BABA ${ }^{3}$
}

\author{
${ }^{1}$ Department of Medicine and Biosystemic Sciences, Faculty of Medical Sciences, Kyushu University; \\ ${ }^{2}$ Department of Respiratory Medicine, Kyushu University Hospital; ${ }^{3}$ Department of Oncology and Social Medicine, \\ Kyushu University Graduate School of Medical Sciences, Higashi-ku, Fukuoka 812-8582, Japan
}

Received July 14, 2020; Accepted July 16, 2021

DOI: $10.3892 / \mathrm{mco} .2021 .2379$

\begin{abstract}
Severe pneumonitis induced by nivolumab, an anti-programmed cell death-1 monoclonal antibody, is a rare but potentially fatal immune-related adverse event. In cases of steroid-refractory pneumonitis, an appropriate therapeutic strategy using anti-tumor necrosis factor- $\alpha$ (TNF- $\alpha$ ) antibody has not been established. A 59-year-old female was diagnosed with hypopharyngeal squamous cell carcinoma. Previous therapies including chemoradiotherapy and throat laryngectomy were performed, but metastatic recurrence appeared in the intrapulmonary and mediastinal lymph nodes. The patient was administered nivolumab. On the 14th day of nivolumab administration, the patient experienced dyspnea and computed tomography of the chest showed multiple consolidations in the right lung. She was diagnosed with nivolumab-induced pneumonitis. Because the pneumonitis was refractory to steroid therapy, she was administered infliximab, and the pneumonitis improved. On the 72nd and 101st days of nivolumab administration, nivolumab-induced pneumonitis re-appeared with an elevated serum TNF- $\alpha$ concentration. In each occurrence of pneumonitis, repetitive administration of infliximab improved the pneumonitis. Repetitive administration of infliximab may
\end{abstract}

Correspondence to: Dr Hitoshi Kusaba, Department of Medicine and Biosystemic Sciences, Faculty of Medical Sciences, Kyushu University, 3-1-1 Maidashi, Higashi-ku, Fukuoka 812-8582, Japan

E-mail: hkusaba@intmed1.med.kyushu-u.ac.jp

Abbreviations: Ab, antibody; CRP, C-reactive protein; CT, computed tomography; CTLA-4, cytotoxic T lymphocyte-associated antigen-4; HNSCC, head and neck squamous cell carcinoma; irAE, immunerelated adverse event; ICI, immune checkpoint inhibitor; PD-1, programmed cell death-1; SCC, squamous cell carcinoma; TNF- $\alpha$, tumor necrosis factor $\alpha$

Key words: head and neck cancer, nivolumab, pneumonitis, infliximab, immunotherapy be effective for treating recurrent nivolumab-induced pneumonitis that is associated with an increased serum TNF- $\alpha$ concentration.

\section{Introduction}

Head and neck cancer is the sixth most common cancer worldwide, accounting for $\sim 6 \%$ of all cases and an estimated $1-2 \%$ of all cancer deaths $(1,2)$. More than $90 \%$ of head and neck cancers are squamous cell carcinomas (SCC). In patients with recurrent or metastatic head and neck squamous cell carcinoma (HNSCC), combination therapy with platinum, fluorouracil, and cetuximab as first-line treatment significantly prolongs overall survival (3). Nivolumab, an anti-programmed cell death-1 (PD-1) monoclonal antibody (Ab), shows a significant improvement in overall survival over chemotherapy in patients with HNSCC that is refractory to platinum-based chemotherapy (4). Nivolumab also has durable clinical benefits in patients with various malignant tumors (5-10).

Anti-PD-1 therapies such as nivolumab and pembrolizumab cause immune-related adverse events (irAEs) including endocrine dysfunction, neurological disorders, hepatitis, nephritis, cardiac insufficiency, colitis, and pneumonitis. Among them, pneumonitis is a relatively rare but potentially fatal adverse event (11). The incidence of pneumonitis associated with anti-PD-1 therapies is $2.7 \%$ for all-grade and $0.8 \%$ for grade $\geq 3$ (12). Cancer immunotherapy guidelines recommend an intermediate or high dose of corticosteroids for anti-PD-1 therapy-induced pneumonitis $(13,14)$. In cases of severe pneumonitis that is refractory to corticosteroids, several immune suppressants such as cyclophosphamide, mycophenolate mofetil, and the anti-tumor necrosis factor alpha (TNF- $\alpha$ ) $\mathrm{Ab}$, infliximab, are recommended. Infliximab is effective for pneumonitis due to anti-PD-1 therapy (15). However, the efficacy and feasibility of repetitive administration of infliximab for recurrent pneumonitis remain unclear. Here, we present a case in which amelioration of recurrent nivolumab-induced severe pneumonitis was induced by repetitive administration of infliximab. 


\section{Case presentation}

A 59-year-old female with a heavy smoking (70 pack-years) and drinking history was diagnosed with SCC of the oropharynx (cT2N0M0) and hypopharynx (cT2NOM0) in 201x-3. She was treated with induction chemotherapy consisting of cisplatin and docetaxel followed by concurrent chemoradiotherapy with tegafur/gimeracil/oteracil (S-1), resulting in a complete response. She also had a history of definitive chemoradiotherapy consisting of cisplatin and 5-fluorouracil for locally advanced esophageal SCC (cT3N1M0) in 201x-1. Although she had undergone a complete resection for local recurrence of the hypopharyngeal SCC in August 201x, metastases to the lung and mediastinal lymph nodes were detected in November $201 \mathrm{x}$ and histologically confirmed as SCCs. She was then treated with nivolumab monotherapy at a standard dose of $3 \mathrm{mg} / \mathrm{kg}$ for metastatic HNSCC. Her Eastern Cooperative Oncology Group performance status was 1 . She had no respiratory symptoms. Blood tests and laboratory examinations showed normal values except for anemia (hemoglobin $9.0 \mathrm{~g} / \mathrm{dl}$ ) and a high level of serum C-reactive protein (CRP; $6.3 \mathrm{mg} / \mathrm{dl})$. The antinuclear antibody test was negative. On the 10th day of the first administration of nivolumab, she complained of fever and a dry cough. Oseltamivir was given for 7 days following immunological diagnosis of influenza B virus infection. However, she was admitted to our hospital because of progressive dyspnea on the 14th day of nivolumab administration. Computed tomography (CT) scans of the chest showed ground-glass opacities in the right lung (Fig. 1A). It was difficult for us to determine whether the CT findings were infectious pneumonia such as pulmonary suppuration or round-glass opacities. We consulted with a pulmonologist and a radiologist and diagnosed. Immunological tests for influenza virus were negative. Other infectious diseases were also ruled out by bacterial sputum/blood/urinary culture and fungal antigen tests. Bronchoscopy and bronchoalveolar lavage revealed a high proportion of lymphocytes: Macrophages $27.5 \%$, neutrophils $46.4 \%$, lymphocytes $26.1 \%$, eosinophils $0 \%$. These results suggested drug-induced lung disease or viral infection. The serum concentration of Krebs von den Lungen-6 was normal, but surfactant protein-A was elevated $(58.6 \mathrm{ng} /$ $\mathrm{ml}$ ). She was finally diagnosed with nivolumab-induced pneumonitis. Nivolumab was then discontinued, and intravenous high-dose methylprednisolone (1,000 mg/day for 3 days) was administered. Prophylactic antibiotics were also started. However, on the 17th day, dyspnea worsened to the extent that intubation was required. CT scans showed that the groundglass opacities in the right lung had worsened (Fig. 1B). Blood tests showed high concentrations of serum CRP $(12.4 \mathrm{mg} / \mathrm{dl})$ and serum TNF- $\alpha(45.2 \mathrm{pg} / \mathrm{ml})$. She was administered a single dose of infliximab $(5 \mathrm{mg} / \mathrm{kg}$ ) for nivolumab-induced pneumonitis that was refractory to high-dose methylprednisolone. One week after administration of infliximab, serum concentrations of CRP and TNF- $\alpha$ were decreased, and CT scans showed marked regression of pulmonary opacities (Fig. 1C). Subsequently, the dosage of prednisolone was tapered to $30 \mathrm{mg}$ daily after $35 \mathrm{mg}$ daily administration for 2 weeks (Fig. 2). On the 72nd day after nivolumab administration, the patient complained of fever, dyspnea, diarrhea, and joint pain. Blood tests showed that the serum level of CRP $(50.0 \mathrm{mg} / \mathrm{dl})$ was elevated again, and CT scans of the chest showed that the
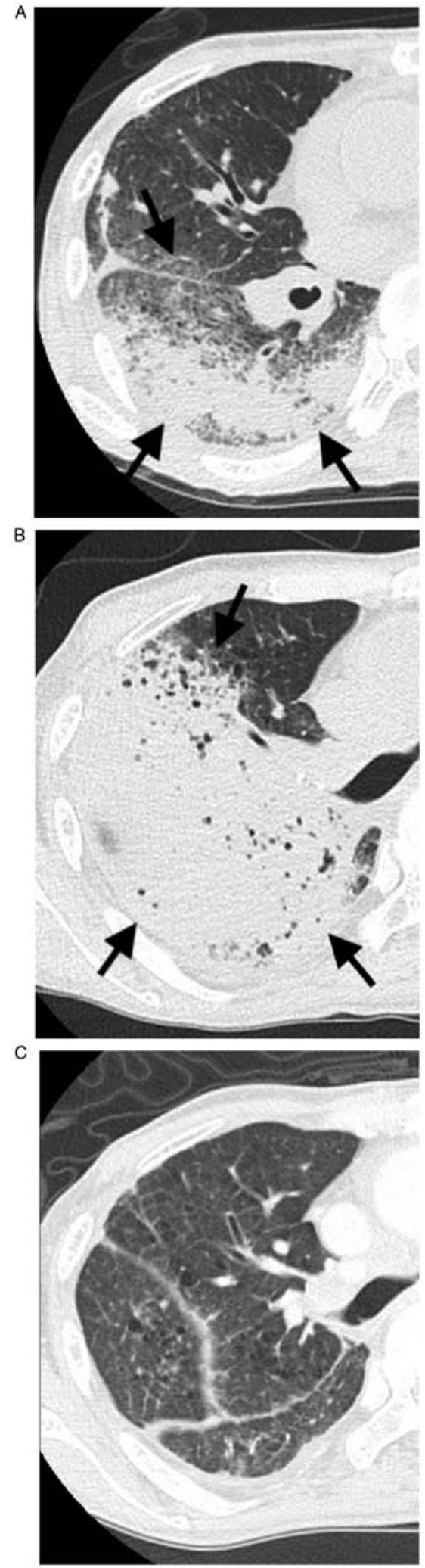

Figure 1. Images show the lungs before and after infliximab treatment with initial nivolumab-induced pneumonia. (A) CT on the 14th day of nivolumab administration revealed GGO (indicated by arrows) in the right lung. (B) CT on the 17th day of nivolumab administration indicated that the GGO (indicated by arrows) in the right lung were exacerbated. (C) After administration of infliximab, GGO disappeared. CT, computed tomography; GGO, groundglass opacities.

pneumonitis had worsened in the right lung (Fig. 3A). Bacterial sputum/blood/urinary culture, the $\beta$-D glucan value, and viral 


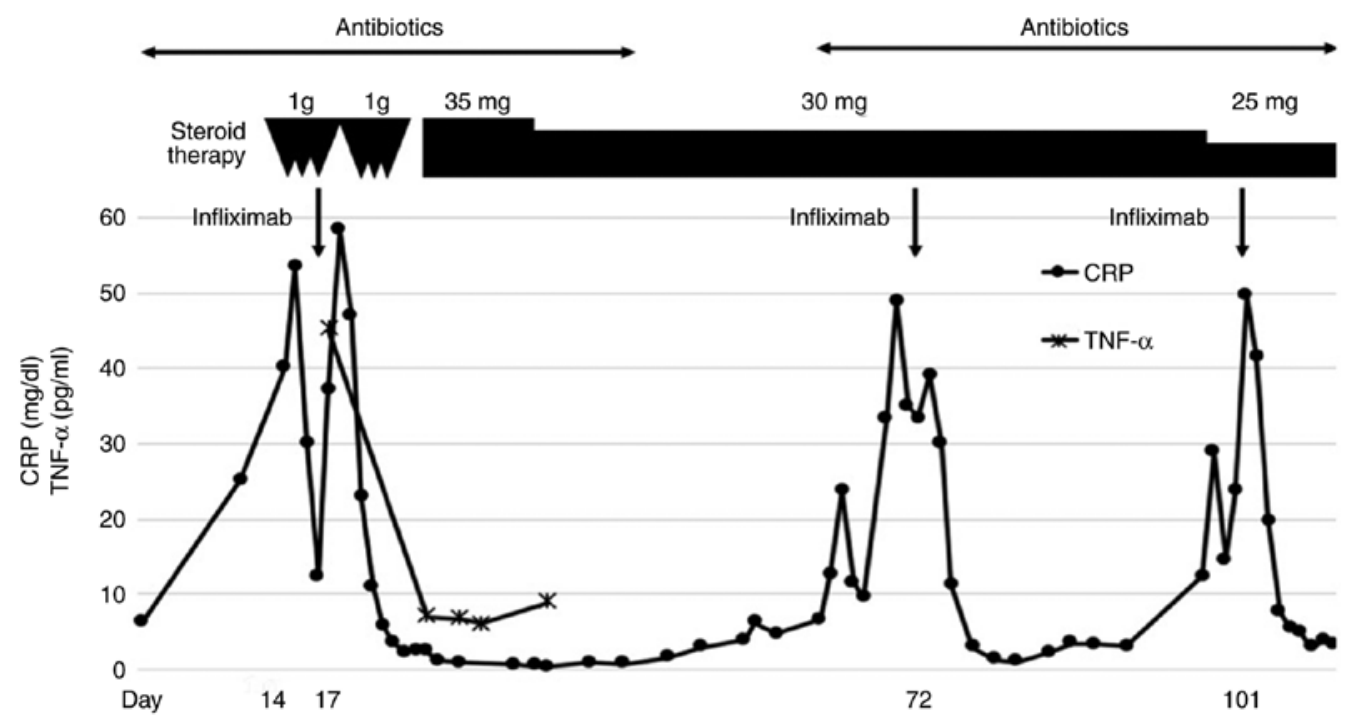

Figure 2. Clinical course of the patient. Administration of infliximab decreased serum concentrations of CRP and TNF- $\alpha$. Black column indicates steroid therapy, the downward arrows indicates administration of infliximab $(5 \mathrm{mg} / \mathrm{kg})$ and the closed circle indicates CRP (mg/dl). Black cross indicates TNF- $\alpha(\mathrm{pg} / \mathrm{ml})$ and the horizontal arrow indicates administration of antibiotics. CRP, C-reactive protein; TNF- $\alpha$, tumor necrosis factor $\alpha$.

antibody tests including influenza virus were all negative. She was thus diagnosed with recurrence of nivolumab-induced pneumonitis. She was administered a single dose of infliximab again on the 70th day because her previous pneumonitis was refractory to high-dose methylprednisolone, and more than 8 weeks had passed since the first dose of infliximab (Fig. 2). The second administration of infliximab improved the pneumonitis (Fig. 3B). Although prednisolone $25 \mathrm{mg}$ daily was continued, pneumonitis relapsed on the 101st day of nivolumab administration without any specific events; nivolumab may have exacerbated the pneumonitis (Fig. 3C). A single dose of infliximab was again administered, and her pneumonitis improved (Fig. 3D). Nivolumab was not re-administered due to severe irAE. We discussed taxanes, S-1, or cetuximab for the next therapy. However, best supportive care was performed because of the poor performance status due to progression of the tumor. The patient died of tumor progression the 121st day after the initial administration of nivolumab. Informed consent was obtained from the patient for publication of a case report.

\section{Discussion}

Immune checkpoint inhibitors (ICIs) targeting the PD-1/ PD-L1 axis and cytotoxic T lymphocyte-associated antigen-4 (CTLA-4) have demonstrated notable antitumor activity across various tumor types. On the other hand, irAEs induced by ICIs have become an important issue. Dermatologic, musculoskeletal, gastrointestinal, hepatic, endocrine, and pulmonary events have been reported (16). Among them, pneumonitis is a serious adverse event that can have a lethal outcome. The incidence of pneumonitis associated with anti-PD-1 Ab is $2.7 \%$ for all-grade and $0.8 \%$ for grade $\geq 3$ (12). Huang et al reported that nivolumab, pembrolizumab, and nivolumab plus ipilimumab therapy are significantly higher risk factors for pneumonitis compared with chemotherapy (17). Generally, the time to onset of pneumonitis associated with anti-PD-1 Ab varies from within a few weeks to months after administration (16).
Several retrospective analyses and systematic reviews investigated the risk factors for ICI-related pneumonitis. Pre-existing pulmonary fibrosis increases the risk of anti-PD-1 Ab-related pneumonitis in patients with non-small cell lung cancer (18). A history of radiotherapy of the lung was also thought to be a risk factor for ICI-related pneumonitis (19). In the present case, pneumonitis occurred $\sim 2$ weeks after administration of nivolumab. Because infectious pneumonia was carefully ruled out, the patient was diagnosed with nivolumabinduced pneumonitis. Although the patient did not have pre-existing pulmonary fibrosis, a history of radiotherapy for locally advanced esophageal SCC may have affected the development of pneumonitis as reported in a previous study (19). Furthermore, previous influenza B virus infection may trigger or worsen nivolumab-induced pneumonitis. Inflammatory cytokines including TNF- $\alpha$ are induced early after influenza infection (20). Although these factors may be associated with occurrence of ICI-related pneumonitis, the mechanisms of steroid refractoriness of pneumonitis have not been clarified.

Regarding the treatment for ICI-induced pneumonitis, the cancer immunotherapy guidelines recommend corticosteroids for treatment of irAEs $(13,14)$. Immunosuppressive drugs such as infliximab or mycophenolate mofetil are recommended for serious irAEs that are refractory to corticosteroids $(13,14)$. Several studies reported that infliximab is effective for anti-CTLA-4 Ab-induced enterocolitis that is refractory to corticosteroids $(21,22)$. Infliximab also improves ICI-induced pneumonitis that is refractory to corticosteroids $(15,23)$. TNF- $\alpha$ is involved in the onset of pneumonitis associated with autoimmune diseases (24). In the present case, respiratory insufficiency and pulmonary opacities did not improve with intravenous high-dose methylprednisolone but with a single dose of infliximab. After improvement in pneumonitis with infliximab, a maintenance dose of prednisolone was continued. However, reactivation of pneumonitis was observed 2 months after the first administration of infliximab, and 1 month after the second administration of infliximab. 

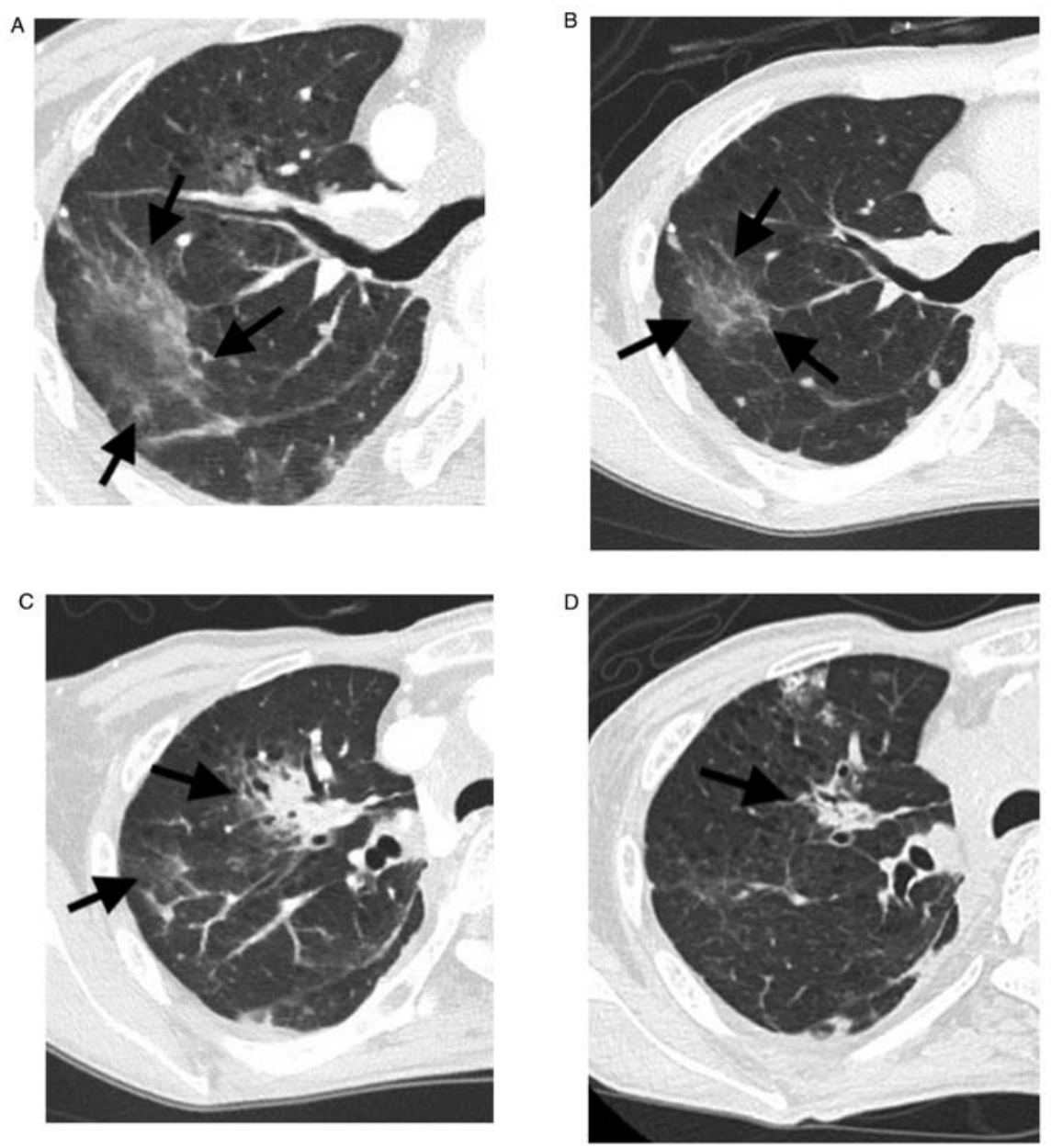

Figure 3. Lungs before and after infliximab treatment with the second and third nivolumab-induced pneumonia. (A) CT on the 72nd day of nivolumab administration showed that pneumonitis (indicated by arrows) was exacerbated in the right lung. (B) Second administration of infliximab improved the pneumonitis (indicated by arrows). (C) CT on the 101st day of nivolumab administration demonstrated that pneumonitis (indicated by arrows) had relapsed in the right lung. (D) Third administration of infliximab improved the pneumonitis (indicated by arrows). CT, computed tomography.

Multiple mechanisms may be associated with recurrence of nivolumab-induced pneumonitis. Activation of $\mathrm{CD} 8^{+}$ $\mathrm{T}$ cells mediates psoriasis-like dermatitis and hepatotoxicity caused by ICIs $(25,26)$. A specific $\mathrm{T}$ cell repertoire such as CD8 that is involved in nivolumab-induced pneumonitis may be decreased after infliximab administration, and then reactivation of the $\mathrm{T}$ cell repertoire may induce recurrence of the pneumonitis. Alternatively, the decrease in TNF- $\alpha$ by infliximab administration could induce the $\mathrm{T}$ cell repertoire. Thus, serum TNF- $\alpha$ may play a critical role in modulating the activity of nivolumab-induced pneumonitis.

In the present case, the serum concentration of TNF- $\alpha$ clearly increased in association with exacerbation of the pneumonitis, and it subsequently decreased in association with amelioration of pneumonitis after infliximab therapy. These observations suggested that TNF- $\alpha$ is directly involved in the activity of nivolumab-induced pneumonitis. The dosing schedule of infliximab, including repetitive administration of infliximab, for steroid-refractory ICI-induced pneumonitis has not been clearly described in the current guidelines for cancer immunotherapy $(13,14)$. Recently, a case was reported of ICI-induced pneumonitis demonstrating transient improvement but re-exacerbation 2 weeks after infliximab therapy, suggesting the possible efficacy of repetitive administration of infliximab (23).
Immune-related colitis that is refractory to corticosteroids is improved by repetitive administration of infliximab when it relapses (27). Although other cytokines are possibly related to exacerbation of ICI-induced pneumonitis such as interleukin-1 and interleukin-6 (28), the recurring nivolumab-induced pneumonitis in the present case is strongly suggested to be mainly dependent on TNF- $\alpha$. Repetitive infliximab therapy is thought to be effective for nivolumab-induced pneumonitis that worsens in accordance with increased serum concentrations of TNF- $\alpha$. Steroid-refractory nivolumab-induced pneumonitis was apparently improved with infliximab therapy. One reason for recurrence of the pneumonitis is thought to be an increase in TNF- $\alpha$ caused by reactivation of autoreactive T cells.

A limitation for this study is that TNF- $\alpha$ at the second and third onset of pneumonitis could not be measured due to insufficient blood sample volume.

In conclusion, repetitive administration of infliximab was effective for the recurring pneumonitis. The present case may provide valuable information to establish an appropriate therapeutic strategy for steroid-refractory ICI-induced pneumonitis.

\section{Acknowledgements}

Not applicable. 


\section{Funding}

No funding was received.

\section{Availability of data and materials}

The datasets used and/or analyzed during the current study are available from the corresponding author on reasonable request.

\section{Authors' contributions}

SU and HK made substantial contributions to the conception and design of the study. SU, MU, HK, KS and HO made substantial contributions to the acquisition of the data. SU and HK drafted the manuscript. SU and $\mathrm{HK}$ confirm the authenticity of all the raw data. SU, HK, MI, KT, HA, KA and EB made substantial contributions to the analysis and interpretation of the data and were involved in revising the manuscript critically for important intellectual content. All authors read and approved the final manuscript.

\section{Ethics approval and consent to participate}

Not applicable.

\section{Patient consent for publication}

Written informed consent was obtained from the patient for publication of the clinical data and images.

\section{Competing interests}

The authors declare that they have no competing interests.

\section{References}

1. Jemal A, Bray F, Center MM, Ferlay J, Ward E and Forman D: Global cancer statistics. CA Cancer J Clin 61: 69-90, 2011.

2. Ferlay J, Soerjomataram I, Dikshit R, Eser S, Mathers C, Rebelo M, Parkin DM, Forman D and Bray F: Cancer incidence and mortality worldwide: Sources, methods and major patterns in GLOBOCAN 2012. Int J Cancer 136: E359-E386, 2015.

3. Vermorken JB, Mesia R, Rivera F, Remenar E, Kawecki A, Rottey S, Erfan J, Zabolotnyy D, Kienzer HR, Cupissol D, et al Platinum-based chemotherapy plus cetuximab in head and neck cancer. N Engl J Med 359: 1116-1127, 2008.

4. Ferris RL, Blumenschein G Jr, Fayette J, Guigay J, Colevas AD, Licitra L, Harrington K, Kasper S, Vokes EE, Even C, et al Nivolumab for recurrent squamous-cell carcinoma of the head and neck. N Engl J Med 375: 1856-1867, 2016.

5. Robert C, Long GV, Brady B, Dutriaux C, Maio M, Mortier L, Hassel JC, Rutkowski P, McNeil C, Kalinka-Warzocha E, et al: Nivolumab in previously untreated melanoma without BRAF mutation. N Engl J Med 372: 320-330, 2015.

6. Brahmer J, Reckamp KL, Baas P, Crinò L, Eberhardt WE, Poddubskaya E, Antonia S, Pluzanski A, Vokes EE, HolgadoE, et al: Nivolumab versus Docetaxel in advanced squamous-cell nonsmall-cell lung cancer. N Engl J Med 373: 123-135, 2015.

7. Borghaei H, Paz-Ares L, Horn L, Spigel DR, Steins M, Ready NE, Chow LQ, Vokes EE, Felip E, Holgado E, et al: Nivolumab versus Docetaxel in advanced nonsquamous non-small-cell lung cancer. N Engl J Med 373: 1627-1639, 2015.

8. Motzer RJ, Escudier B, McDermott DF, George S, Hammers HJ, Srinivas S, Tykodi SS, Sosman JA, Procopio G, Plimack ER, et al Nivolumab versus Everolimus in advanced renal-cell carcinoma. N Engl J Med 373: 1803-1813, 2015.
9. Kang YK, Boku N, Satoh T, Ryu MH, Chao Y, Kato K, Chung HC, Chen JS, Muro K, Kang WK, et al: Nivolumab in patients with advanced gastric or gastro-oesophageal junction cancer refractory to, or intolerant of, at least two previous chemotherapy regimens (ONO-4538-12, ATTRACTION-2): A randomised, double-blind, placebo-controlled, phase 3 trial. Lancet 390: 2461-2471, 2017.

10. Le DT, Uram JN, Wang H, Bartlett BR, Kemberling H, Eyring AD, Skora AD, Luber BS, Azad NS, Laheru D, et al: PD-1 blockade in tumors with mismatch-repair deficiency. N Engl J Med 372: 2509-2520, 2015.

11. Nishino M, Sholl LM, Hodi FS, Hatabu H and Ramaiya NH: Anti-PD-1-related pneumonitis during cancer immunotherapy. N Engl J Med 373: 288-290, 2015.

12. Nishino M, Giobbie-Hurder A, Hatabu H, Ramaiya NH and Hodi FS: Incidence of programmed cell death 1 inhibitor-related pneumonitis in patients with advanced cancer: A systematic review and meta-analysis. JAMA Oncol 2: 1607-1616, 2016.

13. Brahmer JR, Lacchetti C, Schneider BJ, Atkins MB, Brassil K, Caterino JM, Chau I, Ernstoff MS, Gardner JM, Ginex P, et al: Management of immune-related adverse events in patients treated with immune checkpoint inhibitor therapy: American society of clinical oncology clinical practice guideline. J Clin Oncol 36: 1714-1768, 2018.

14. Champiat S, Lambotte O, Barreau E, Belkhir R, Berdelou A, Carbonnel F, Cauquil C, Chanson P, Collins M, Durrbach A, et al: Management of immune checkpoint blockade dysimmune toxicities: A collaborative position paper. Ann Oncol 27: 559-574, 2016.

15. Sanchez GO, Jahn K, Savic S, Zippelius A and Läubli H: Treatment of mycophenolate-resistant immune-related organizing pneumonia with infliximab. J Immunother Cancer 6: 85, 2018.

16. Postow MA, Sidlow R and Hellmann MD: Immune-related adverse events associated with immune checkpoint blockade. N Engl J Med 378: 158-168, 2018.

17. Huang Y, Fan H, Li N and Du J: Risk of immune-related pneumonitis for PD1/PD-L1 inhibitors: Systematic review and network meta-analysis. Cancer Med 8: 2664-2674, 2019.

18. Yamaguchi T, Shimizu J, Hasegawa T, Horio Y, Inaba Y, Yatabe Y and Hida T: Pre-existing pulmonary fibrosis is a risk factor for anti-PD-1-related pneumonitis in patients with non-small cell lung cancer: A retrospective analysis. Lung Cancer 125: 212-217, 2018.

19. Cui P, Liu Z, Wang G, Ma J, Qian Y, Zhang F, Han C, Long Y, $\mathrm{Li} \mathrm{Y}$, Zheng X, et al: Risk factors for pneumonitis in patients treated with anti-programmed death-1 therapy: A case-control study. Cancer Med 7: 4115-4120, 2018.

20. Kido H: Influenza virus pathogenicity regulated by host cellular proteases, cytokines and metabolites, and its therapeutic options. Proc Jpn Acad Ser B Phys Biol Sci 91: 351-368, 2015.

21. Beck KE, Blansfield JA, Tran KQ, Feldman AL, Hughes MS, Royal RE, Kammula US, Topalian SL, Sherry RM, Kleiner D, et al: Enterocolitis in patients with cancer after antibody blockade of cytotoxic T-lymphocyte-associated antigen 4. J Clin Oncol 24: 2283-2289, 2006.

22. Johnston RL, Lutzky J, Chodhry A and Barkin JS: Cytotoxic T-lymphocyte-associated antigen 4 antibody-induced colitis and its management with infliximab. Dig Dis Sci 54: 2538-2540, 2009.

23. Sawai Y,Katsuya Y, Shinozaki-Ushiku A, Iwasaki A,Fukayama M, Watanabe $\mathrm{K}$ and Nagase T: Rapid temporal improvement of pembrolizumab-induced pneumonitis using the anti-TNF- $\alpha$ antibody infliximab. Drug Discov Ther 13: 164-167, 2019.

24. Gosset P, Perez T, Lassalle P, Duquesnoy B, Farre JM, Tonnel AB and Capron A: Increased TNF-alpha secretion by alveolar macrophages from patients with rheumatoid arthritis. Am Rev Respir Dis 143: 593-597, 1991.

25. Tanaka R, Ichimura Y, Kubota N, Saito A, Nakamura Y, Ishitsuka Y, Watanabe R, Fujisawa Y, Kanzaki M, Mizuno S, et al: Activation of CD8 T cells accelerates anti-PD-1 antibody-induced psoriasis-like dermatitis through IL-6. Commun Biol 3: 571, 2020.

26. Zen Y and Yeh MM: Hepatotoxicity of immune checkpoint inhibitors: A histology study of seven cases in comparison with autoimmune hepatitis and idiosyncratic drug-induced liver injury. Mod Pathol 31: 965-973, 2018.

27. Minor DR, Chin K and Kashani-Sabet M. Infliximab in the treatment of anti-CTLA4 antibody (ipilimumab) induced immunerelated colitis. Cancer Biother Radiopharm 24: 321-325, 2009.

28. Fishman JA, Hogan JI and Maus MV: Inflammatory and infectious syndromes associated with cancer immunotherapies. Clin Infect Dis 69: 909-920, 2019.

This work is licensed under a Creative Commons Attribution-NonCommercial-NoDerivatives 4.0 International (CC BY-NC-ND 4.0) License. 